\title{
Interrelationships between Prey and Predators and How Predators Choose Their Prey to Maximize Their Utility Functions
}

\author{
Asmaa Idmbarek, Yamna Achik, Imane Agmour, Hajar Nafia, and Youssef El Foutayeni \\ Analysis, Modeling and Simulation Laboratory, Hassan II University of Casablanca, Morocco \\ Correspondence should be addressed to Youssef El Foutayeni; foutayeni@gmail.com
}

Received 1 January 2021; Revised 28 January 2021; Accepted 9 February 2021; Published 27 February 2021

Academic Editor: Wei-Chiang Hong

Copyright (c) 2021 Asmaa Idmbarek et al. This is an open access article distributed under the Creative Commons Attribution License, which permits unrestricted use, distribution, and reproduction in any medium, provided the original work is properly cited.

\begin{abstract}
In this work, we model the relationship between prey and predators by studying the interactive behavior of this prey-predator model and using the change of prey. The objective is to maximize the profit function of each predator by seeking the strategy provided by each predator to maximize its profit. To do so, we maximize this utility function being constrained by balance equations between biomass and trophic, and we show that this last problem is completely equivalent to finding the generalized Nash equilibrium point. To calculate it, we use the conditions of Karush-Kuhn-Tucker and we show that it indeed a linear complementarity problem.
\end{abstract}

\section{Introduction}

The Lotka-Volterra model is one of the primeval predatorprey models to be based on sturdy mathematical principles. It forms the key of many models used nowadays in the analysis of population dynamics [1-4]. Unfortunately, the LotkaVolterra model, unworkable though it is, proposes that uncomplicated predator-prey interactions canister in periodic behavior of the species. Reasoning drastically this unanticipated since if a prey species increment, it boosts growth of its predator. More predators however devour more prey and the species of which starts to decrease. With less food around, the predator species decreases, and when it is under enough, this avows the prey species to escalate and the whole cycle starts over again. Depending on the detailed system, such oscillations can grow or decay or go into a stable limit cycle oscillation or even exhibit chaotic behavior, although in the latter case there must be at least three interaction species or the model has to have some delay terms.

The pyramid of the marine food chain is grouped into five phases as shown in Figure 1. (i) In the first phase, at the base of the pyramid, we find the phytoplankton. They are planktonic organisms that produce half of the oxygen that all heterotrophic living things and volcanoes consume and end up on the surface of the water in the form of colored expanses. We note that phytoplankton is preyed upon by other sea creatures

(ii) In the second phase of the pyramid, we find the zooplankton, which are plankton animal organisms. These creatures produce light and energy and rise to the surface at night to feed on phytoplankton and descend during the day to deeper waters. Among these organisms, mention may be made of mesozooplankton

(iii) In the third phase, we find the prey that feeds on phytoplankton and zooplankton. As an example of prey, the five small pelagic are mentioned, namely, Sardina pilchardus, Sardinella, Engraulis encrasicolus, Trachurus, and Scomber colias. In this paper, we focus on Sardina pilchardus and Engraulis 


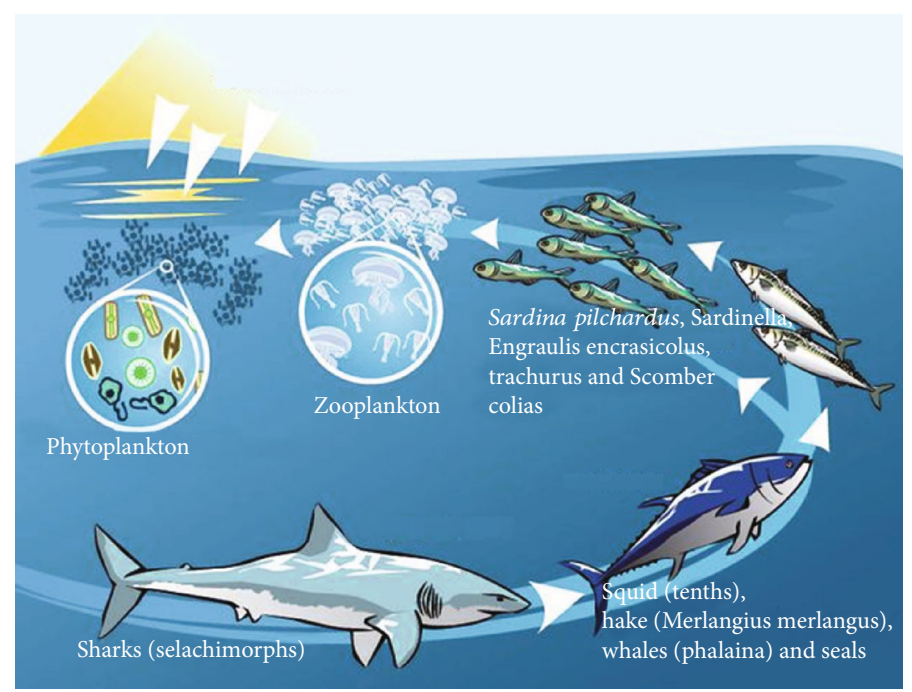

FIGURE 1: The pyramid of the marine food chains.

encrasicolus. Sardina pilchardus belongs to the Clupeidae family and is a coastal pelagic species. Highdensity aggregates are distributed throughout Morocco. However, the highest concentrations are very unstable from year to year and season to season. Engraulis encrasiculis is a species fished mainly by pelagic trawls and purse seines; it is found in the shallows of coastal areas and is found up to $150 \mathrm{~m}$ depth. We add, in this work, as a hypothesis predation between these last two species of prey and planktonic organisms as well as predators. Let us add that the two preys interact for food

(iv) In the fourth phase of the pyramid, we find predators. Examples of predators that we cite are squid (tenths), hake (Merlangius merlangus), whales (phàlaina), and seals. Squids (tenths) mainly attack fish, crustaceans, and other molluscs and feed on zooplankton. Hake (Merlangius merlangus) can be found at a depth between 10 and $200 \mathrm{~m}$ but, more commonly, between 30 and $100 \mathrm{~m}$. Hakes breed from January to July and lay their eggs mainly (but not exclusively) in March and April. Whales (phàlaina) are recognized as playing an important ecological role in the oceans (keystone species), but it has also been shown that this role continues after their death. For millions of years, dead whales have played an important role in food webs. Whales act as a biological pump; they feed on zooplankton. In this paper, he assumes that these species are both predatory and prey

(v) In the last phase of the pyramid, we find that superpredators like sharks (selachimorphs) are present in all the oceans of the globe and in some large rivers; most sharks breed in the ocean

The ecologist Murdoch [5] was the premier person who purposed the term switching in 1969 to characterize the situ- ation where a predator eats improperly more of the most typical of prey. Ahead of Murdoch precisely eight years previous in 1962, the geneticist Clarke [6] described an akin phenomenon and termed it "apostatic selection." Since this instant, the term switching has principally been used by ecologists, whilst apostatic selection has been used by reason of this; they have been used to describe different attitudes of frequency-dependent selection. The modification of prey has been part of the scientific literature since around 1960, but since the first works, Hassel [7] has proposed that the interest in prey switching decayed since it is difficult to demonstrate whether it has or is occurring.

The switching prey has been widely studied by researchers from a variety of backgrounds, which has been a rich and varied literature. In 2017, Suebcharoen [8] studied the behavior of a predator-prey model with switching and stage structure for predators. The bounded positive solution, the equilibria, and the stability are determined for the differential delay equation system. In [9], Tansky defined a mathematical model of two preys and one predator system in which the switching property of predation is investigated. Based on an assumption that predators captured prey in an abundant habitat, after a decrease in the population of prey species, the predator moves to another abundant habitat. Khan et al. [10] studied an interaction of prey and predator species where the prey species have the defense capacity of the group. They used the carrying capacity of prey as the bifurcation parameter. You can find more examples on switching models in [11-16]. Recently, Serra [17] discussed a preliminary study on the possible connection between the Lotka-Volterra model and predator-prey utility functions. Also, they defined a generalization of the utility functions to the predator-prey population, seeing that the utility functions depend on parameters such as the strategies adopted, physical efficiency of the predator versus the prey, environmental conditions, and prey prudence. In the second work in 2014, Serra [18] considered a mathematical model to describe the interacting behavior of predator and prey. This model is based on the utility functions of the competing 


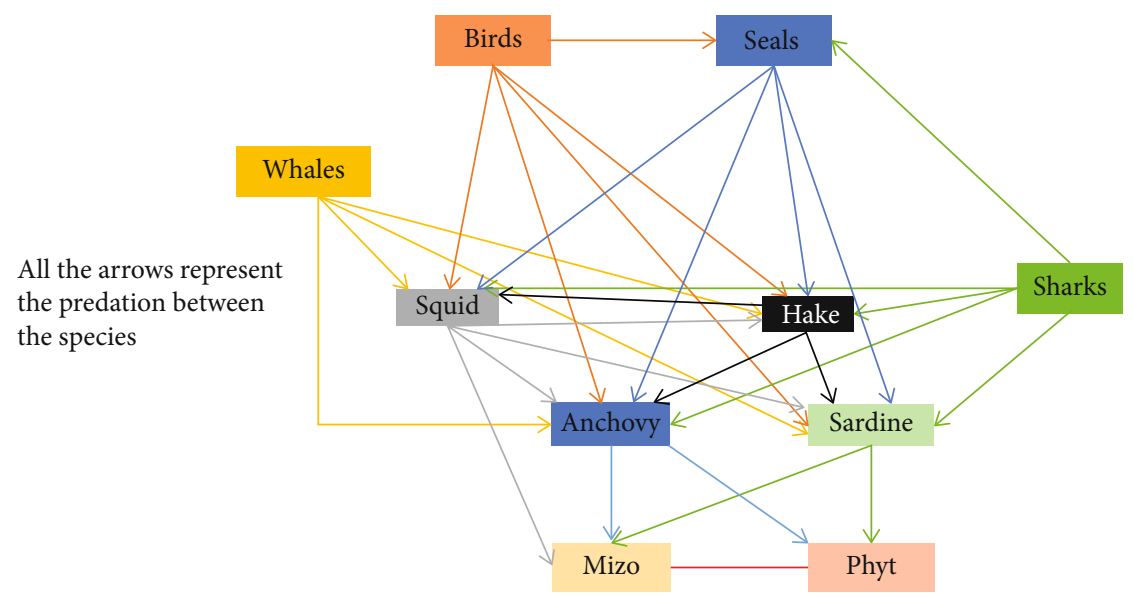

Figure 2: Interaction between ten species.

individuals. Such functions depend on various parameters that suitably describe animal instincts, considering both physical and environmental conditions. Two possible strategies have been considered for each individual: to race or to be quiet.

This paper is formulated as follows. In the next section, we propose a model for ten species based on a usual balance equation. In Section 3, we define the utility function of predators and prey and some parameters that depend on the environmental and physical conditions of these species. In Section 4, we gave a Nash equilibrium problem which is the equivalence of our problem and then we transfer it into a linear complementarity problem to solve it.

\section{Switching-Prey Model}

We use the prey switching to describe the choice between different species as shown in Figure 2. The evolution of the biomass of the species is given by the following mathematical equation:

$$
\dot{B}_{i}=r_{i} B_{i}\left(1-\frac{B_{i}}{k_{i}}\right)+\sum_{j=1}^{n} x_{i j} B_{i}-\beta_{i} \sum_{j=1}^{m} x_{j i} B_{i},
$$

where $B_{i}$ is the biomass of species $i, x_{i j}$ is the trophic flow of species $i$ (predator) to species $j$ (prey), $r_{i}$ is the growth rate of species $i$, and $k_{i}$ is the load capacity of species $i$ and $\beta_{i}=1 / k_{i}$.

The model is formulated under the following assumptions: (i) interactions with other species and (ii) interaction between these predators.

Phytoplankton is among the best food for mesozooplankton, anchovy, and sardine with $x_{21}, x_{31}$, and $x_{41}$ strategies associated to each species, respectively, as shown in Figure 2. The evolution of the biomass of phytoplankton is given by

$$
\dot{B}_{1}=r_{1} B_{1}\left(1-\frac{B_{1}}{k_{1}}\right)-\beta_{1}\left(x_{21}+x_{31}+x_{41}\right) B_{1} .
$$

Mesozooplankton eats phytoplankton with $x_{21}$, and it was eaten by anchovy, sardine, and squid with $x_{32}, x_{42}$, and $x_{52}$ strategies associated to each species, respectively, as shown in Figure 2. The evolution of the biomass of mesozooplankton is given by

$$
\dot{B}_{2}=r_{2} B_{2}\left(1-\frac{B_{2}}{k_{2}}\right)+\left(x_{21}+x_{22}\right) B_{2}-\beta_{2}\left(x_{22}+x_{32}+x_{42}+x_{52}\right) B_{2} .
$$

Anchovy eats phytoplankton and mesozooplankton with $x_{31}$ and $x_{32}$ strategies, and it was eaten by squid, hake, birds, seals, whales, and sharks with $x_{53}, x_{63}, x_{73}, x_{83}, x_{93}$, and $x_{103}$ strategies associated to each species, respectively, as shown in Figure 2. The evolution of the biomass of anchovy is given by

$\dot{B}_{3}=r_{3} B_{3}\left(1-\frac{B_{3}}{k_{3}}\right)+\left(x_{31}+x_{32}\right) B_{2}-\beta_{3}\left(x_{53}+x_{63}+x_{73}+x_{83}+x_{93}+x_{103}\right) B_{3}$.

Sardine eats phytoplankton and mesozooplankton with $x_{41}$ and $x_{42}$ strategies, and it was eaten by squid, hake, birds, seals, whales, and sharks with $x_{54}, x_{64}, x_{74}, x_{84}, x_{94}$, and $x_{104}$ strategies associated to each species, respectively, as shown in Figure 2. The evolution of the biomass of sardine is given by

$$
\dot{B}_{4}=r_{4} B_{4}\left(1-\frac{B_{4}}{k_{4}}\right)+\left(x_{41}+x_{42}\right) B_{4}-\beta_{4}\left(x_{54}+x_{64}+x_{74}+x_{84}+x_{94}+x_{104}\right) B_{4}
$$

Squid eats mesozooplankton, anchovy, sardine, and hake with $x_{52}, x_{53}, x_{54}$, and $x_{56}$ strategies, and it was eaten by hake, birds, seals, whales, and sharks with $x_{65}, x_{75}, x_{85}, x_{95}$, and $x_{105}$ strategies associated to each species, respectively, as shown in Figure 2. The evolution of the biomass of squid is given by

$\dot{B}_{5}=r_{5} B_{5}\left(1-\frac{B_{5}}{k_{5}}\right)+\left(x_{52}+x_{53}+x_{54}+x_{56}\right) B_{5}-\beta_{5}\left(x_{65}+x_{75}+x_{85}+x_{95}+x_{105}\right) B_{5}$.

Hake eats anchovy, sardine, and squid with $x_{63}, x_{64}$, and 
$x_{65}$ strategies, and it was eaten by squid, birds, seals, whales, and sharks with $x_{56}, x_{76}, x_{86}, x_{96}$, and $x_{106}$ strategies associated to each species, respectively, as shown in Figure 2 . The evolution of the biomass of hake is given by

$$
\dot{B}_{6}=r_{6} B_{6}\left(1-\frac{B_{6}}{k_{6}}\right)+\left(x_{63}+x_{64}+x_{65}\right) B_{6}-\beta_{6}\left(x_{56}+x_{76}+x_{86}+x_{96}+x_{106}\right) B_{6} .
$$

Birds eat anchovy, sardine, squid, hake, and seals with $x_{73}$ , $x_{74}, x_{75}, x_{76}$, and $x_{78}$ strategies associated to each species, respectively, as shown in Figure 2. The evolution of the biomass of birds is given by

$$
\dot{B}_{7}=r_{7} B_{7}\left(1-\frac{B_{7}}{k_{7}}\right)+\left(x_{73}+x_{74}+x_{75}+x_{76}+x_{78}\right) B_{6}
$$

Seals eat anchovy, sardine, squid, and hake with $x_{83}, x_{84}$, $x_{85}$, and $x_{86}$ strategies, and they were eaten by birds and sharks with $x_{78}$ and $x_{108}$ strategies associated to each species, respectively, as shown in Figure 2. The evolution of the biomass of seals is given by

$$
\dot{B}_{8}=r_{8} B_{8}\left(1-\frac{B_{8}}{k_{8}}\right)+\left(x_{83}+x_{84}+x_{85}+x_{86}\right) B_{8}-\beta_{8}\left(x_{78}+x_{108}\right) B_{8} .
$$

Whales eat anchovy, sardine, squid, and hake with $x_{93}$, $x_{94}, x_{95}$, and $x_{96}$ strategies associated to each species, respectively, as shown in Figure 2. The evolution of the biomass of whales is given by

$$
\dot{B}_{9}=r_{9} B_{9}\left(1-\frac{B_{9}}{k_{9}}\right)+\left(x_{93}+x_{94}+x_{95}+x_{96}\right) B_{9} .
$$

Sharks eat anchovy, sardine, squid, hake, and seals with $x_{103}, x_{104}, x_{105}, x_{106}$, and $x_{108}$ strategies associated to each species, respectively. The evolution of the biomass of sharks is given by

$\dot{B}_{10}=r_{10} B_{10}\left(1-\frac{B_{10}}{k_{10}}\right)+\left(x_{103}+x_{104}+x_{105}+x_{106}+x_{108}\right) B_{10}$.

The expression of the biomass is given by

$$
B_{i}=k_{i}+\frac{k_{i}}{r_{i}} \sum_{j=1}^{n} x_{i j}-\frac{1}{r_{i}} \sum_{j=1}^{m} x_{j i} B_{i}
$$

Otherwise, we have

$$
\sum_{j=1}^{m} x_{j i}=\sum_{j=1}^{m} e_{j}^{T} X_{i}
$$

TABLE 1: Strategies of ten species.

\begin{tabular}{lcccccccccc}
\hline & $\mathrm{P}$ & $\mathrm{M}$ & $\mathrm{A}$ & $\mathrm{Sa}$ & $\mathrm{Sq}$ & $\mathrm{H}$ & $\mathrm{B}$ & $\mathrm{Se}$ & $\mathrm{W}$ & $\mathrm{Sh}$ \\
$\mathrm{P}$ & 10 & 1 & 8 & & & & & & \\
$\mathrm{M}$ & & 8 & 10 & 6 & & & & & \\
$\mathrm{~A}$ & & & 3 & 3 & 16 & 4 & 5 & 1 & 0.9 \\
$\mathrm{Sa}$ & & & & 2.9 & 20 & 1 & 0.2 & 6 & 0.02 \\
$\mathrm{Sq}$ & & & & & 2 & 63 & 2 & 0.04 & 1 \\
$\mathrm{H}$ & & & & 0.05 & & 8 & 20 & 28 & 30 \\
$\mathrm{~B}$ & & & & & & & & & \\
Se & & & & & & 0.1 & & & 45 \\
W & & & & & & & & & \\
Sh & & & & & & & & & \\
\hline
\end{tabular}

TABLE 2: Values of parameters and utility function of each species.

\begin{tabular}{lccccccc}
\hline & $\begin{array}{c}\text { Biomass } \\
10^{2}\end{array}$ & $k \times 10^{2}$ & $r$ & $a$ & $b$ & $\beta$ & Utility function $U$ \\
\hline $\mathrm{P}$ & 0.01 & 2 & 1 & 4 & 0 & 0.05 & 0 \\
$\mathrm{M}$ & 0.03 & 1 & 2 & 3 & -0.5 & 0.1 & 189.5 \\
$\mathrm{~A}$ & 2.45 & 9 & 5 & 2 & 0.3 & 0.01 & 113.626 \\
$\mathrm{Sa}$ & 1.63 & 5 & 9 & 1 & 0.2 & 0.02 & 1580.684 \\
$\mathrm{Sq}$ & 0.51 & 2 & 5.4 & 1 & 0.4 & 0.05 & 2022.598 \\
$\mathrm{H}$ & 2.05 & 3 & 6 & 1 & -0.2 & 0.03 & 11341.11 \\
$\mathrm{~B}$ & 3.15 & 3 & 8 & 1 & 0.2 & 0.03 & 7907.544 \\
$\mathrm{Se}$ & 15.05 & 5 & 1 & 1 & 0.05 & 0.01 & 6855.469 \\
$\mathrm{~W}$ & 0.80 & 1 & 5 & 1 & 0.1 & 0.1 & 7688.382 \\
$\mathrm{Sh}$ & 2.99 & 2.5 & 7 & 1 & 0.2 & 0.04 & 10443.3844 \\
\hline & & & & & & &
\end{tabular}

where $e_{j}$ is the vector whose all coefficients are zero except that of index $j$ and this coefficient of index $j$ is equal to 1 and we have

$$
\sum_{j=1}^{n} x_{i j}=e_{i}^{T} \sum_{j=1}^{n} X_{j}
$$

Using (13) and (14), we have

$$
B=\operatorname{diag}\left(\frac{1}{R}\right)\left[K R-\sum_{j=1}^{n} A^{(j)} X_{j}\right]
$$

where $K_{i j}=k_{j} \delta_{i j}$ with $\delta_{i j}$ is Kronecker's symbol, $A^{(j)}=I-k$ $I^{(j)}$ and $I^{(j)}=I_{i k}^{(j)}=\delta_{i j}, \forall k=1, \cdots, n$, and $R=\left(r_{1}, \cdots, r_{n}\right)^{T}$.

We introduce that the utility functions depend on certain parameters that describe the species behavior (preference, accessibility of prey, and togetherness) by the following functions

$$
U_{j}(X)=\sum_{k=1}^{n} x_{k j}\left(c_{j k}+a_{k} B_{k}\right)+b_{j} B_{j}
$$




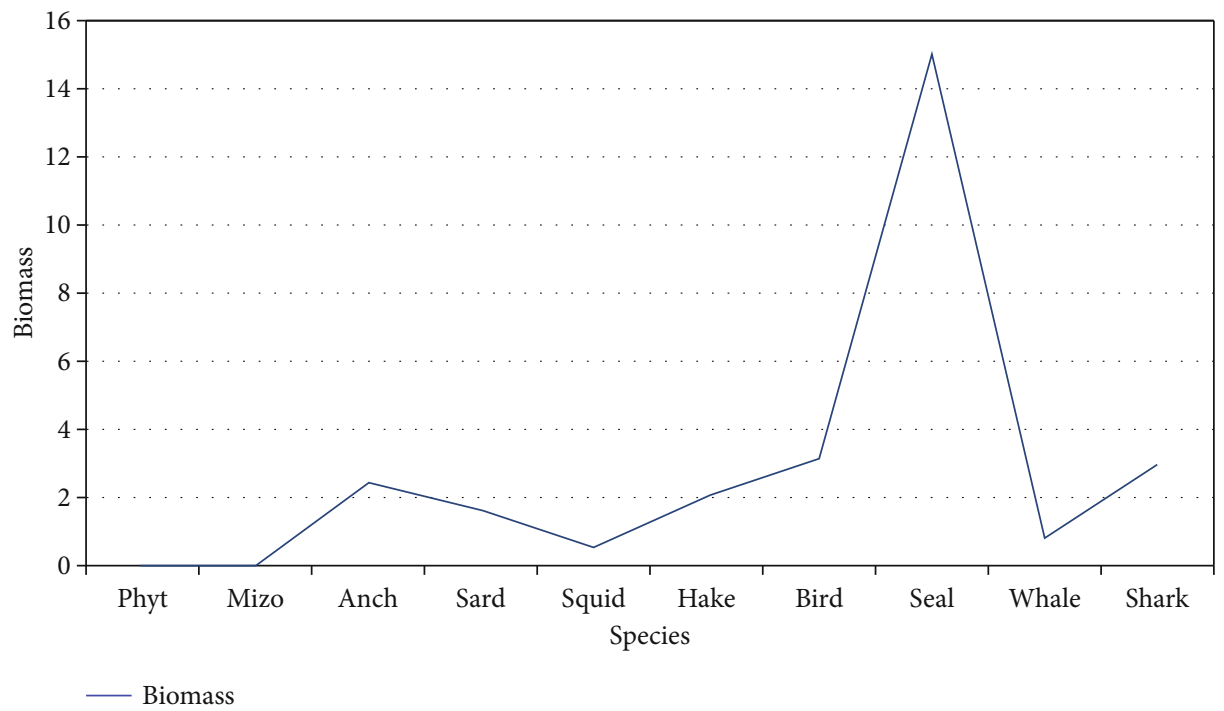

Figure 3: Biomass of ten species.

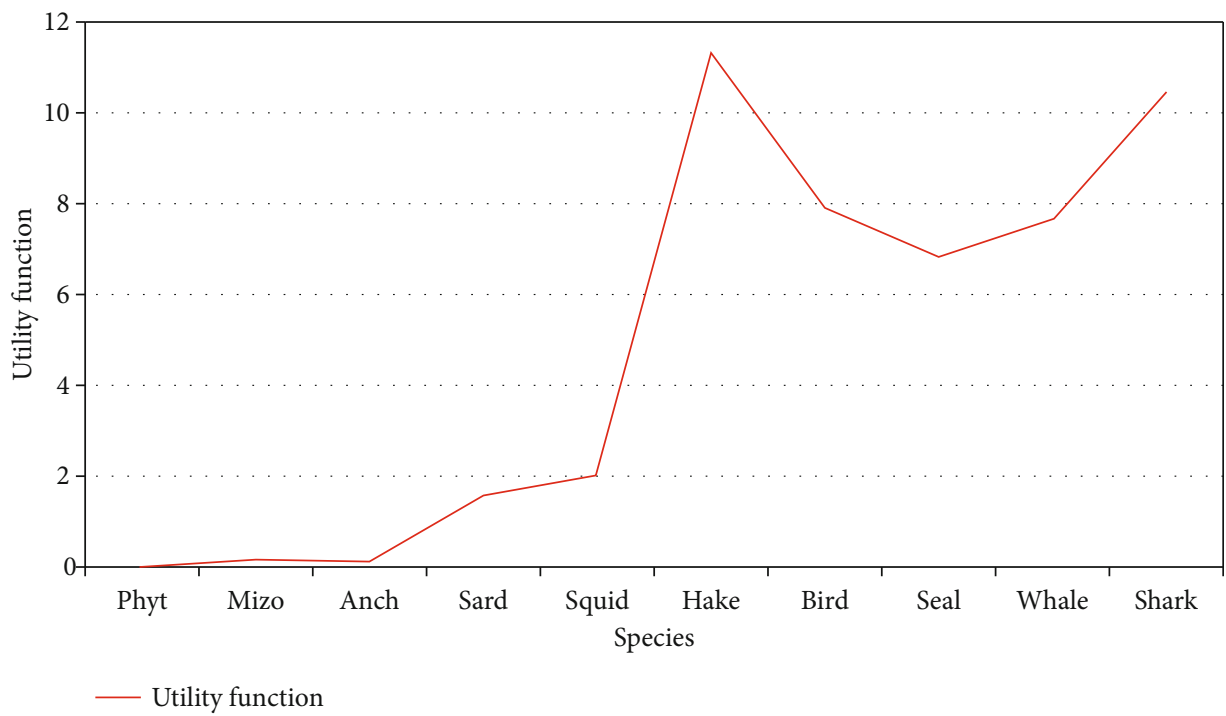

FIgURE 4: Utility function of ten species.

where $c_{j i}$ is the preference of predator $i$ for prey $j, a_{i}$ is related to the accessibility of prey $j$, and $b_{i}$ is related to the togetherness of predator $i$.

Now, we will give the expression of utility functions $U_{i}$ in function of $x$ in matrix form.

According to (16), we have $U_{j}(X)=X_{j}^{T}\left(c_{j}+\operatorname{diag}(a) B\right)$ $+b_{j} B_{j}$ with the notation $x y=\left(x_{1} y_{1}, \cdots, x_{n} y_{n}\right)^{T}$ for all vectors $x$ and $y$ and $c_{j}=\left(c_{1 i}, c_{2 i}, \cdots, c_{n i}\right)^{T}$. We use (15) to find $U_{j}(X$ )$=X_{j}^{T}\left[c_{j}+D\left(K R-\sum_{j=1}^{n} A^{(j)} X_{j}\right)\right]+b_{j} B_{j}$, where $D$ is the $n \times n$ diagonal matrix with $D_{i i}=a_{i} / r_{i}$ for all $i$ and $D_{i j}=0$ for all $i$ $\neq j$.
As $B_{j}=k_{j}+\left(k_{j} / r_{j}\right) e_{j}^{T} \sum_{k=1}^{n} X_{k}-\left(1 / r_{j}\right) \sum_{k=1}^{n} e_{k}^{T} X_{j}$, we have $U_{j}(X)=X_{j}^{T}\left(c_{j}+D-D \sum_{k=1}^{n} A^{(k)} X_{k}\right)+b_{j} k_{j}+\frac{b_{j} k_{j}}{r_{j}} e_{j}^{T} \sum_{k=1}^{n} X_{k}-\frac{b_{j}}{r_{j}} \sum_{k \neq j}^{n} e_{k}^{T} X_{j}$ $=X_{j}^{T}\left(c_{j}+D-D \sum_{k=1}^{n} A^{(k)} X_{k}\right)+b_{j} k_{j}-\frac{b_{j}}{r_{j}} \sum_{k=1}^{n} e_{k}^{T} X_{j}+\frac{b_{j} k_{j}}{r_{j}} e_{j}^{T} X_{j}+\frac{b_{j} k_{j}}{r_{j}} e_{j}^{T} \sum_{k \neq j}^{n} X_{k}$.

Hence,

$$
U_{j}(X)=X_{j}^{T}\left(c_{j}+D-D \sum_{k=1}^{n} A^{(k)} X_{k}-\frac{b_{j}}{r_{j}} \sum_{k=1}^{n} e_{k}+\frac{b_{j} k_{j}}{r_{j}} e_{j}\right)+\frac{b_{j} k_{j}}{r_{j}} e_{j}^{T} \sum_{k \neq j}^{n} X_{k}+b_{j} k_{j} .
$$


Strategy of species should not result in nonsense situations. There are constraints. For all species $j$, its predation is enough to get biomass larger than a constant $B_{0}$ which is positive $B(X)$ $\geqslant B_{0}>0$, that is, $A^{(j)} X_{j} \leqslant I-B_{0}-\sum_{k \neq j}^{n} A^{(k)} X_{k}$, and its strategy must be positive $X_{j} \geqslant 0$ for all $j$.

\section{Generalized Nash Equilibrium}

We recall that $\left(X_{1}^{*}, X_{2}^{*}, \cdots, X_{n}^{*}\right)$ is called a generalized Nash equilibrium point, if and only if, for all $j, X_{j}^{*}$ is a solution of problem $\left(P_{j}\right)$

$$
\left(P_{j}\right) \begin{cases}\operatorname{Max} U_{j}(X) & \\ \text { subject to } & \\ & A^{(j)} X_{j} \leqslant I-B_{0}-\sum_{k \neq j}^{n} A^{(k)} X_{k} \\ & X_{j} \geqslant 0 \\ & \left(X_{k}\right)_{k \neq j} \text { is given. }\end{cases}
$$

For all $j$, the essential conditions of Karush-Kuhn-Tucker applied to the problem $\left(P_{j}\right)$ require that if $X_{j}^{*}$ is a solution of the problem $\left(P_{j}\right)$ then there exist constants $u_{j} \in \mathbb{R}_{+}^{n}, v_{j} \in \mathbb{R}_{+}^{n}$, and $\lambda_{j} \in \mathbb{R}_{+}^{n}$ such that

$$
\left\{\begin{array}{l}
D A^{(j)} X_{j}^{*}-c_{j}-D K R+D \sum_{k=1}^{n} A^{(k)} X_{k}^{*}+\frac{b_{j}}{r_{j}} \sum_{k=1}^{n} e_{k}-\frac{b_{j} k_{j}}{r_{j}} e_{j}+A_{j}^{T} \lambda_{j}-u_{j}=0 \\
A^{(j)} X_{j}^{*}+v_{j}=K R-B_{0}-\sum_{k \neq j}^{n} A^{(k)} X_{k}^{*} \\
\left(u_{j}\right)^{T} X_{j}^{*}=\left(v_{j}\right)^{T} \lambda_{j}=0 .
\end{array}\right.
$$

It is immediately seen from (20) that

$$
\left\{\begin{array}{l}
u_{j}=D A^{(j)} X_{j}^{*}-c_{j}-D K R+D \sum_{k=1}^{n} A^{(k)} X_{k}^{*}+\frac{b_{j}}{r_{j}} \sum_{k=1}^{n} e_{k}-\frac{b_{j} k_{j}}{r_{j}} e_{j}+A_{j}^{T} \lambda_{j}, \\
v_{j}=K R-B_{0}-\sum_{k=1}^{n} A^{(k)} X_{k}^{*}, \\
\left(u_{j}\right)^{T} X_{j}^{*}=\left(v_{j}\right)^{T} \lambda_{j}=0 .
\end{array}\right.
$$

To maintain the biodiversity of species, it is natural to assume that all biomasses remain positive, that is, $B_{j}>0$ for all $j$; therefore, $v>0$. As the scalar product of $v_{j}$ and $\lambda_{j}$ is zero,

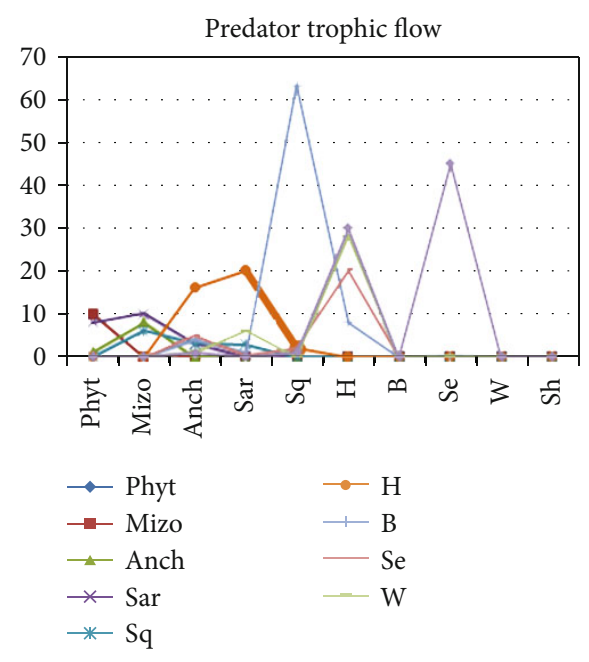

Figure 5: Predator trophic flow.

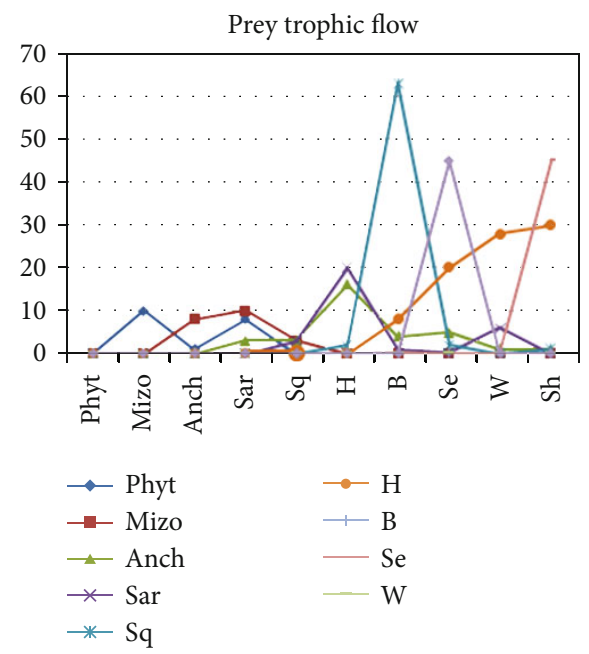

FIgURe 6: Prey trophic flow.

so $\lambda_{j}=0$ for all $j$. In what follows of this paper, we denote by $v=v_{j}$. So we have the following expressions

$$
\left\{\begin{array}{l}
u_{j}=D A^{(j)} X_{j}^{*}-c_{j}-D K R+D \sum_{k=1}^{n} A^{(k)} X_{k}^{*}+\frac{b_{j}}{r_{j}} \sum_{k=1}^{n} e_{k}-\frac{b_{j} k_{j}}{r_{j}} e_{j}, \\
v=K R-B_{0}-\sum_{k=1}^{n} A^{(k)} X_{k}^{*}, \\
\left(u_{j}\right)^{T} X_{j}^{*}=0 .
\end{array}\right.
$$

Let us denote by $z=\left(X_{1}^{*}, X_{2}^{*}, \cdots, X_{n}^{*}, 0\right)^{T}$ and $w=\left(u_{1}, .\right.$. $\left.\cdots, u_{n}, v\right)$ 


$$
\begin{aligned}
M & =\left[\begin{array}{ccccc}
2 D A^{(1)} & D A^{(2)} & \cdots & D A^{(n)} & I \\
D A^{(1)} & 2 D A^{(2)} & \cdots & D A^{(n)} & I \\
D A^{(1)} & D A^{(2)} & \cdots & D A^{(n)} & I \\
\vdots & \vdots & \vdots & \vdots & \vdots \\
D A^{(1)} & D A^{(2)} & \cdots & 2 D A^{(n)} & I \\
-A^{(1)} & -A^{(2)} & \cdots & -A^{(n)} & I
\end{array}\right], \\
q & =\left(\begin{array}{c}
\frac{b_{1}}{r_{1}} \sum_{k} e_{k}-\frac{b_{1} k_{1}}{r_{1}} e_{1}-c_{1}-D K R \\
\frac{b_{2}}{r_{2}} \sum_{k} e_{k}-\frac{b_{2} k_{2}}{r_{2}} e_{2}-c_{2}-D K R \\
\vdots \\
\frac{b_{n}}{r_{n}} \sum_{k} e_{k}-\frac{b_{n} k_{n}}{r_{n}} e_{n}-c_{n}-D K R \\
K R-B_{0}
\end{array}\right) .
\end{aligned}
$$

Hence, our problem is equivalent to the linear complementarity problem $\operatorname{LCP}(M, q)$. (For more details, see El Foutayeni [19].) Find vectors $z$ and $w \in \mathbb{R}^{n+n^{2}}$ such that $w=M z+q \geqslant 0, w, z \geqslant 0$ and $z^{T} w=0$. It is simple to verify that matrix $M$ is $P$-matrix, which proves the existence and the uniqueness of the solution. For more details, see [2024]. We use the method of Achik et al. [22] because of the rapidity of convergence to calculate this solution.

\section{Conclusion and Discussion}

In this part, we have done the strategies of 10 species (phytoplankton, mesozooplankton, anchovy, sardine, squid, hake, birds, seals, whales, and sharks). Then, we calculate the biomass of all species and the utility function.

Table 1 shows the interaction of each species compared to the other species.

Phytoplankton has no interaction with itself. It is a prey of the mesozooplankton, anchovy, and sardine; these three species want to maximize their gains, so they must make a strategy that equals 10,1 , and 8 , respectively.

Mesozooplankton has no interaction with itself. It is a prey of the anchovy, sardine, and squid, so they must make a strategy that equals 8,10 , and 6 , respectively.

Anchovy has no interaction with itself. It is a prey of the sardine, squid, hake, birds, seals, whales, and sharks; therefore, they must make a strategy which equals $3,3,16,4,5$, 1 , and 0.9 , respectively, and so on for the other species.

In the following table, we give the parameters (biomass, $k$, $r, a, b$, and $\beta$ ) that we will be needed to calculate the utility function and strategies for each species. The last column represents the utility function for each species as shown in Table 2.

It shows the key role of certain hake species in our implementations (Figures 3 and 4), which presents the opposite of the key species, situations of great variability and adaptability to new ones.
Figures 5 and 6 represent the best strategies adopted by the ten species to maximize its gains; the difference is that Figure 5 gives the ten species as predators and Figure 6 gives the ten species as preys.

The study of the balance of the model revealed a high sensitivity compared to the definition of the utility functions.

This article deals with a preliminary methodological approach to the study of animal behaviors, in particular, with regard to the struggle between predators and preys, in order to make a prediction of the behavior of interactive individuals. The utility functions proposed in this study are conditioned by more parameters which describe the physical conditions, the environmental conditions, and the strategies they adopt.

\section{Data Availability}

There are no data.

\section{Conflicts of Interest}

The authors declare that they have no conflicts of interest.

\section{References}

[1] H. J. Gold, Mathematical Modeling of Biological Systems, John Wiley \& Sons, 1977.

[2] J. D. Murray, Lectures on Nonlinear-Differential-Equation Models in Biology, Oxford University Press, 1977.

[3] V. A. A. Jansen and A. M. DeRoos, "The role of space in reducing predator-prey cycles, the geometry of ecological interactions simplifying spacial compelxity," Cambridge University Press, pp. 183-201, 2000.

[4] W. Feng, X. Lu, and R. J. Donavan, "Population dynamics in a model for territory acquisition, discrete and continuous dynamical systems, added volume," Feng, vol. 2001, pp. 156165, 2001, No. Special.

[5] W. W. Murdoch, "Switching in general predators: experiments on predator specificity and stability of prey populations," Ecological Monographs, vol. 39, no. 4, pp. 335-354, 1969.

[6] B. C. Clarke, "Balanced polymorphism and the diversity of sympatric species," in Taxonomy and Geography, D. Nichols, Ed., pp. 47-70, Systematics Association Publication, Oxford, 1962.

[7] M. P. Hassell, The Spatial and Temporal Dynamics of Host Parasitoid Interactions, Oxford University Press, 2002.

[8] T. Suebcharoen, "Analysis of a predator-prey model with switching and stage-structure for predator," International Journal of Differential Equations, vol. 2017, Article ID 2653124, 11 pages, 2017.

[9] M. Tansky, "Switching effect in prey-predator system," Journal of Theoretical Biology, vol. 70, no. 3, pp. 263-271, 1978.

[10] Q. J. Khan, E. Balakrishnan, and G. C. Wake, "Analysis of a predator-prey system with predator switching," Bulletin of Mathematical Biology, vol. 66, no. 1, pp. 109-123, 2004.

[11] P. Prajneshu and P. Holgate, "A prey-predator model with switching effect," Journal of Theoretical Biology, vol. 125, no. 1, pp. 61-66, 1987.

[12] E. Teramoto, K. Kawasaki, and N. Shigesada, "Switching effect of predation on competitive prey species," Journal of Theoretical Biology, vol. 79, no. 3, pp. 303-315, 1979. 
[13] A. Das and G. P. Samanta, "Modeling the fear effect on a stochastic prey-predator system with additional food for the predator," Journal of Physics A: Mathematical and Theoretical, vol. 51, no. 46, article 465601, 2018.

[14] A. M. Ramos and T. Roubicek, "Nash equilibria in noncooperative predator-prey games," Applied Mathematics and Optimization, vol. 56, no. 2, pp. 211-241, 2007.

[15] A. Das and G. P. Samanta, "Stochastic prey-predator model with additional food for predator," Physica A: Statistical Mechanics and its Applications, vol. 512, pp. 121-141, 2018.

[16] N. S. Goel, S. C. Maitra, and E. W. Montroll, "On the Volterra and Other Nonlinear Models of Interacting Populations," in Reviews of Modern Physics, vol. 43, no. 2pp. 231-276, Academic Press, New York, 1971.

[17] N. Serra, "Utility functions and Lotka-Volterra model: a possible connection in predator-prey game," Journal of Game Theory, vol. 3, pp. 31-34, 2014.

[18] N. Serra, "Possible utility functions for predator-prey game," Journal of Game Theory, vol. 3, pp. 11-18, 2014.

[19] Y. El Foutayeni, Modélisation et Étude Mathématique et Informatique d'un Modèle Bioéconomique d'Exploitation d'Espèces Marines en Compétition, thèse Université Cadi Ayyad, Marrakech Maroc, 2011.

[20] R. W. Cottle, J. S. Pang, and R. E. Stone, The Linear Complementarity Problem, Academic Press, New York, 1992.

[21] K. G. Murty, "On the number of solutions to the complementarity problem and spanning properties of complementary cones," Linear Algebra and its Applications, vol. 5, no. 1, pp. 65-108, 1972.

[22] Y. Achik, A. Idmbarek, H. Nafia, I. Agmour, and Y. El Foutayeni, "A fast algorithm for solving a class of the linear complementarity problem in a finite number of steps," Abstract and Applied Analysis, vol. 2020, Article ID 8881915, 8 pages, 2020.

[23] Y. Elfoutayeni and M. Khaladi, "Using vector divisions in solving the linear complementarity problem," Journal of Computational and Applied Mathematics, vol. 236, no. 7, pp. 19191925, 2012.

[24] Y. El Foutayeni and M. Khaladi, "General characterization of a linear complementarity problem," American journal of modeling and Optimization, vol. 1, pp. 1-5, 2003. 